\title{
ATOMIC SCALE OBSERVATIONS OF THE CHEMICAL COMPOSITION OF A METAL/CERAMIC INTERFACE
}

\author{
Ho Jang and David N. Seidman \\ Department of Materials Science and Engineering and the Materials Research Center \\ Northwestern University \\ Evanston, IL 60208-3108 USA \\ Karl L. Merkle \\ Materials Science Division \\ Argonne National Laboratory \\ Argonne, IL 60439 USA \\ (Received February 20, 1992) \\ (Revised March 13, 1992)

\section{Introduction}

The heterophase interface between a metal and a ceramic is of great practical importance because of the ubiquitousness of this interface in composite materials, thin film technology and electronic packaging systems. The nature of the chemical bond at a metal/ceramic interface is very important in determining how well these two disparate materials adhere to one another, and ultimately the performance of this heterophase interface in service. On the basic side the question of the nature and strength of the chemical bond at a metal/ceramic interface has been addressed recently from a first principles point-of-view $[1,2]$. In addition, much experimental effort has been expended recently employing high resolution electron microscopy (HREM) to determine the terminating plane on the oxide side of metal/metal oxide heterophase interfaces by comparing observed HREM images with computer simulated images [3-5].

In this paper we present a combined transmission electron microscopy, HREM and atom-probe field-ion microscopy (APFIM) study of a $\mathrm{Cu} / \mathrm{MgO}$ heterophase interface produced by internal oxidation of a $\mathrm{Cu}(\mathrm{Mg})$ alloy. This heterophase interface is an interesting one as it consists of joining a noble free-electron metal $(\mathrm{Cu})$ to a strongly heteropolar metal oxide (MgO). We demonstrate, for the first time, that by combining these three microscopies it is possible to determine the chemical identity of the terminating plane on the oxide side of a $\mathrm{Cu} / \mathrm{MgO}\{111\}$-type interface directly without any deconvolution of the experimental data. In particular, we demonstrate that the bonding across a $\mathrm{Cu} / \mathrm{MgO}\{111\}$-type interface, in a common $<111\rangle$ direction, has the sequence CulOIMgl... and not $\mathrm{Cu} / \mathrm{MglOI} .$. via APFIM measurements of this highly localized chemistry.

\section{ExperimentaL Procedures}

Three different $\mathrm{Cu}(\mathrm{Mg})$ alloys were prepared by melting ASARCO copper $(99.998+$ at.\% pure) and Johnson Matthey magnesium ( 99.98 at.\% pure) in a graphite crucible sealed under an argon atmosphere in a quartz tube, to form small cylindrically-shaped ingots weighing $\approx 26$ gm each. The particular alloy compositions prepared were $\mathrm{Cu}-0.16$ at. $\% \mathrm{Mg}, \mathrm{Cu}-0.7$ at.\% $\mathrm{Mg}$ and $\mathrm{Cu}-2.8$ at.\% $\mathrm{Mg}$; these $\mathrm{Mg}$ concentrations correspond to singlephase solid-solution alloys [6]. The ingots were rolled into $0.125 \mathrm{~mm}$ thick sheets for transmission electron microscopy (TEM) and HREM studies, or drawn into $250 \mu \mathrm{m}$ diameter wires for APFIM studies. 
$\mathrm{Cu} / \mathrm{MgO}$ internal interfaces were formed by internally oxidizing these alloy specimens utilizing the Rhines pack method [7,8]; this pack consists of a powder mixture of $\mathrm{Cu}$ plus $\mathrm{Cu}_{2} \mathrm{O}$ plus $\mathrm{Al}_{2} \mathrm{O}_{3}(1: 1: 1)$. To realize a high probability of finding an $\mathrm{MgO}$ precipitate in an APFIM specimen, experiments were performed to determine the optimum $\mathrm{Mg}$ concentration, internal oxidation temperature and time for achieving a high number density $\left(>5.10^{15}\right.$ $\mathrm{cm}^{-3}$ ) and small diameter precipitates $(<20 \mathrm{~nm})$. The optimum composition is a $\mathrm{Cu}-2.8$ at.\% $\mathrm{Mg}$ alloy, at an internal oxidizing temperature of $1173 \mathrm{~K}$ and an oxidizing time of $1200 \mathrm{~s}$ for both the thin sheets and wires. Those experiments demonstrate that to achieve the desired conditions the most critical parameter is the $\mathrm{Mg}$ concentration, and neither the temperature nor the time of the internal oxidizing treatment appear to be especially critical.

For the TEM and HREM studies $3 \mathrm{~mm}$ diameter disks are punched out of the thin sheets, and a twin-jet polisher (Tenupol) employing a $30 \mathrm{vol} . \%$ nitric acid $/ 70 \mathrm{vol} . \%$ methanol solution at $243 \mathrm{~K}$ is used to prepare electron transparent thin regions. The APFIM specimens are electropolished to a sharply-pointed tip with an approximately $65.8 \mathrm{~nm}$ radius in the region of the 111 pole, after the internal oxidation procedure, utilizing an electrolytic solution with the composition $100 \mathrm{~g} \mathrm{Na}_{2} \mathrm{CrO}_{4}: 4 \mathrm{H}_{2} \mathrm{O}$ in $900 \mathrm{ml}$ of acetic acid. A stainless steel cathode in the form of a $25 \mathrm{~mm}$ diameter circular loop is used to electropolish the wire-shaped specimens [9]. To examine a wire-shaped specimen by TEM a specially fabricated double-tilt stage is employed for an Hitachi $700 \mathrm{H} 200 \mathrm{kV}$ electron microscope [9]. This double-tilt stage is unique as it allows us to examine the same wire FIM specimen both prior to and after an atom probe study as well as at different stages of the electropolishing process [9].

\section{Experiments with_Transmission_and_High_Resolution_Electron_Microscopies}

First, conventional TEM is used to determine both the number density of $\mathrm{MgO}$ precipitates and also the size distribution of precipitates. As found in previous investigations of fcc systems, the precipitates exhibit a cube-oncube orientation relation with the $\mathrm{Cu}$ matrix $[5,10]$. Conventional TEM micrographs of $\mathrm{MgO}$ precipitates in a $\mathrm{Cu}$ matrix exhibit typical "coffee-bean" strain-field contrast [11]. The histogram of the diameters of the MgO precipitates is quite broad [12]. The actual diameter, however, of a precipitate is difficult to estimate from a brightfield electron microscope image, since the shape and amount of strain-field contrast depend on the direction of the electron beam relative to a specimen's crystallography $[13,14]$. Therefore, to determine the exact dimensions of a precipitate the Moiré fringe method is used -- it employs a double-diffraction technique [15]. For instance, we observed the parallel (111) Moire fringes of a faceted MgO precipitate with the projected image plane close to (123). And, therefore, the shape of the fringes represents the shape of the precipitate viewed along a [123] direction. The Moire pattern in this case is a result of the difference between the interplanar spacings of the $\mathrm{Cu}$ and $\mathrm{MgO}$ (111) lattice planes. The fringe spacing is $1.5 \mathrm{~nm}$ and the average size of the precipitates studied by this technique is $19.5 \mathrm{~nm}$.

HREM is used to investigate the atomic structure of a $\mathrm{Cu} / \mathrm{MgO}$ (111\}-type interface. Axial illumination in an Hitachi H9000 HREM allows the direct observation of the configuration of atoms near an interface when proper operating conditions are met [10]. Figure 1 exhibits an HREM image (defocus value is $69.4 \mathrm{~nm}$ at $300 \mathrm{kV}$ ) of an $\mathrm{MgO}$ precipitate in a $\mathrm{Cu}$ matrix with a common [100] zone axis for both phases. (We also recorded HREM images employing a common [110] zone axis for both phases.) The diameter of this $\mathrm{MgO}$ precipitate is $13 \mathrm{~nm}$ and the octahedron exhibits truncations along $\{010\}$-type planes, indicating that the equilibrium shape has not been fully developed. The HREM images demonstrate that the orientation relationship is cube-on-cube with an octahedralshaped precipitate that is faceted on $\{111\}$ planes. The lattice misfit parameter $(\eta)$ is given by

$\eta=2\left[\left(\mathrm{a}_{\mathrm{MgO}}-\mathrm{aCu}\right) /\left(\mathrm{a}_{\mathrm{MgO}}+\mathrm{aCu}\right)\right]$, where the a's are the lattice parameters of the two phases, and its experimental value is 0.1483 in agreement with the calculated value. This lattice misfit is accommodated by a combination of localized misfit dislocations and elastic straining at $\mathrm{Cu} / \mathrm{MgO}(111\}$-type interfaces. 


\section{Atom-Probe Field-Ion Microscope Experiments}

For the chemical analysis of a $\mathrm{Cu} / \mathrm{MgO}$ (111\}-type interface a sharply-pointed atom-probe field-ion microscope specimen with a tip radius of approximately $65.8 \mathrm{~nm}$, in the region of the 111 pole, is employed. TEM micrographs of an FIM specimen containing $\mathrm{MgO}$ precipitates show uniformly aligned $\mathrm{MgO}$ precipitates exhibiting a directional consistency with respect to the fiber axis of the wire. This axis is a [111] direction as determined from careful TEM tilting experiments. Hence, this observation is consistent with the known experimental results on wire textures of recrystallized $\mathrm{Cu}$ [16].

The same specimen was then transferred to our atom probe for a chemical analysis of a $\mathrm{Cu} / \mathrm{MgO}$ (111) interface. Figure 2 is an FIM micrograph exhibiting an $\mathrm{MgO}$ precipitate in a $\mathrm{Cu}$ matrix. Note that the precipitate shows well-developed contrast features outlining its atomic scale geometry. The approximate diameter of this precipitate is $7.3 \mathrm{~nm}$. The atom probe analysis is performed at a background pressure of $1.2 \cdot 10^{-8} \mathrm{~Pa}$ and a constant tip temperature of $35 \mathrm{~K}$. The pulse fraction (f) -- the ratio of the pulse voltage to the steady-state dc voltage -- is maintained at 0.1 , and a pulse frequency of $15 \mathrm{~Hz}$ is used to dissect the specimen on an atomic scale using the pulsed field-evaporation technique [17]. The detection efficiency is maintained at a constant value of 0.0062 , via software in our fully computer-controlled atom probe; the steady state dc voltage is automatically increased by $10 \mathrm{Vdc}$ for every 1000 field-evaporation pulses if no event is detected. This highly controlled procedure results in the continuous and smooth dissection, on an atom-by-atom basis [17], of a series of (111) planes as well as other planes on the surface of the approximately hemispherical FIM tip. The probe hole in the channel electron multiplier array used to view a specimen was placed at a distance from the tip such that its projected diameter covered approximately 70 atoms [18].

Figure 3 is an integral profile of the cumulative number of $\mathrm{Mg}$ or $\mathrm{O}$ ions versus the cumulative number of $\mathrm{Cu}$ plus $\mathrm{Mg}$ plus $\mathrm{O}$ ions of another $\mathrm{MgO}$ precipitate uncovered during a random area analysis. The projected diameter of the probe hole on the tip is smaller than the diameter of the $\mathrm{MgO}$ precipitate; this implies no correction to the data is required because of a matrix contribution to the precipitate's composition. It is seen from this integral profile that the matrix is essentially pure $\mathrm{Cu}$; prior to the $\mathrm{Cu} / \mathrm{MgO}$ (111) interface only 13 oxygen events were detected out of a total of $10,899 \mathrm{Cu}$ plus $\mathrm{O}$ plus $\mathrm{Mg}$ events for a bulk oxygen concentration of $\approx 10^{-3} \mathrm{at}$. $\mathrm{fr}$. $\mathrm{O}$; in addition, only one $\mathrm{Mg}$ event was detected for a bulk $\mathrm{Mg}$ concentration of $\approx 9 \cdot 10^{-5} \mathrm{at}$. fr. $\mathrm{Mg}$. Note carefully that the the outermost (222) plane of ions of the MgO precipitate consists solely of oxygen ions, and the second (222) plane consists solely of magnesium ions. (At this point the specimen failed catastrophically, presumably because the evaporation field of a magnesium ion is considerably lower than that of an oxygen ion.) The depth resolution of this integral profile is equal to the interplanar spacing along the $<111>$ direction in the MgO precipitate -$\left(\mathrm{d}_{222}\right)_{\mathrm{MgO}}=\mathrm{a}_{0} /(2 \sqrt{3})=0.121 \mathrm{~nm}$, where $\mathrm{a}_{\mathrm{O}}$ is the lattice parameter of $\mathrm{MgO}(0.420 \mathrm{~nm})$. We have obtained the same result for other octahedral-shaped precipitates by also analyzing along <111>-type direcrions across $\mathrm{Cu} / \mathrm{MgO}$ \{111\}-type interface planes. The crystal structure of $\mathrm{MgO}$ is $\mathrm{NaCl}$-type (rock salt structure) and, therefore, the compositions of point-defect free $\{111\}$-type planes alternate from 100 at.\% oxygen to 100 at.\% magnesium as one travels along a $<111>$-type direction from the $\mathrm{Cu}$ matrix to a common $<111>$-type direction in the $\mathrm{MgO}$ precipitate. Thus our experimental results demonstrate directly -- that is, without data deconvolution -- that the bonding across a $\mathrm{Cu} / \mathrm{MgO}\{111\}$-type interface has the sequence $\mathrm{CulO}|\mathrm{Mg}| \ldots$ and not $\mathrm{Cu} / \mathrm{Mg} \mid \mathrm{Ol} \ldots$.

\section{Conclusions}

We have demonstrated that it is possible to determine directly the chemical composition of a metal/ceramic heterophase interface on an atomic scale by using a combination of conventional transmission and high resolution electron microscopies to locate and determine the structure of a metal/ceramic interface. And then using atom-probe 
field-ion microscopy measurements to ascertain the chemical identities of the ions at a heterophase interface as a function of atomic position across an interface. The first application of this approach is made to a $\mathrm{Cu} / \mathrm{MgO}\{111\}$ type interface that was created by the internal oxidation of a Cu-2.8 at.\% Mg alloy at $1173 \mathrm{~K}$ for $1200 \mathrm{~s}$. The depth resolution of the composition profile, across this interface in a $\left\langle 111>\right.$ direction, is equal to $\mathrm{a}_{\mathrm{MgO}} /(2 \sqrt{3})=$ $0.121 \mathrm{~nm}$, where $\mathrm{aMgO}$ is $0.420 \mathrm{~nm}$. In conclusion, the terminating plane of $\mathrm{MgO}$ at a $\mathrm{Cu} / \mathrm{MgO}$ \{111\}-type interface is shown to be oxygen and not magnesium via very direct atom probe field-ion microscope studies.

\section{Acknowledgements}

This research is supported by the U. S. Department of Energy Office of Basic Energy Sciences grant No. DE-FG02-89ER45403 (Dr. J. B. Darby Jr., grant officer). It also utilized central facilities of the National Science Foundation funded Materials Research Center at Northwestern University. We wish to thank Drs. X. W. Lin and W. A. Chiou for help with specimen preparation and high resolution electron microscopy respectively, and Mr. David Chan for useful discussions.

\section{Beferences}

1. A. J. Freeman and Chun Li, in Metal-Ceramic Interfaces: Proceedings of an Intermational Workshop, edited by M. Rühle, A. G. Evans, M. F. Ashby and J. P. Hirth (Pergamon, Oxford, 1990), pp. 2-8.

2. P. Blöchl, G. P. Das, H. F. Fischmeister, and U. Schönberger, in Metal-Ceramic Interfaces: Proceedings of an International Workshop, edited by M. Rühle, A. G. Evans, M. F. Ashby and J. P. Hirth (Pergamon, Oxford, 1990), pp. 9-14.

3. R. Gronsky, Ultramicroscopy, 24, 155 (1988).

4. G. Necker and W. Mader, Phil. Mag. Letts. 58, 205 (1988); W. Mader, Z. Metallkde. 80, 139 (1989).

5. W. Mader and G. Necker, in Metal-Ceramic Interfaces: Proceedings of an International Workshop, edited by M. Rühle, A. G. Evans, M. F. Ashby and J. P. Hirth (Pergamon, Oxford, 1990), pp. 222-233.

6. M. Hansen and K. Anderko, Constitution of Binary Alloys, 2nd ed. (McGraw-Hill, New York, 1958), pp. 594-596; R. Hultgren, P. D. Desai, D. T. Hawkins, M. Gleiser, and K. K. Kelley, Selected Values of the Thermodynamic Properties of Binary Alloys (American Society for Metals, Metals Park, Ohio, 1973), pp. 750-755.

7. F. N. Rhines, Trans. AIME 137, 246 (1940).

8. F. N. Rhines, W. A. Johnson, and W. A. Anderson, Trans. AIME 147, 205 (1942).

9. B. W. Krakauer, J. G. Hu, S. M. Kuo, R. L. Mallick, A. Seki, D. N. Seidman, J. P. Baker, and R. J. Loyd, Rev. Sci. Instrum. 61, 3390 (1990).

10. K. L. Merkle, Ultramicroscopy 37, 130 (1991); in Metal-Ceramic Interfaces: Proceedings of an International Workshop, edited by M. Rühle, A. G. Evans, M. F. Ashby and J. P. Hirth (Pergamon, Oxford, 1990), pp. 242-249; K. L. Merkle, M. I. Buckett, and Y. Gao, to appear in proceedings of the International Symposium on Metal/Ceramic Interfaces, Irsee, Germany (1992).

11. M. F. Ashby and L. M. Brown, Phil. Mag. 8, 1083 (1963).

12. D. J. Pedder, E. D. Boyes, and G. C. Smith, Metal Science J. 12, 437 (1976).

13. R. Hattenbauer and F. Haider, Scripta Metall. Mater. 25, 1173 (1991).

14. U. Dahmen, Ultramicroscopy 30, 102 (1989).

15. W. Kesternich, Mat. Res. Soc. Symp. Proc. 62, 229 (1986).

16. C. S. Barrett and T. B. Massalski, Structure of Metals , 3rd ed. (McGraw-Hill, New York, 1966), pp. 568-569.

17. D. N. Seidman, J. Phys. F: Metal Phys. 3, 393 (1973); A. S. Berger, D. N. Seidman and R. W. Balluffi, Acta Metall. 21, 123 \& 134 (1973); D. N. Seidman, in Radiation Damage in Metals, edited by N. L. Peterson and S. D. Harkness (American Society for Metals, Metals Park, Ohio, 1976), pp. 28-57; D. N. Seidman, Mater. Res. Soc. Symp. Proc. 138, 315 (1989); D. N. Seidman, Mater. Res. Soc. Symp. Proc. 139, 25 (1989).

18. S. M. Kuo, A. Seki, Y. Oh, and D. N. Seidman, Phys. Rev. Lett. 65, 199 (1990); J. G. Hu and D. N. Seidman, Phys. Rev. Lett. 65, 1615 (1990); D. N. Seidman, Mater. Sci. Eng. A137, 57 (1991). 


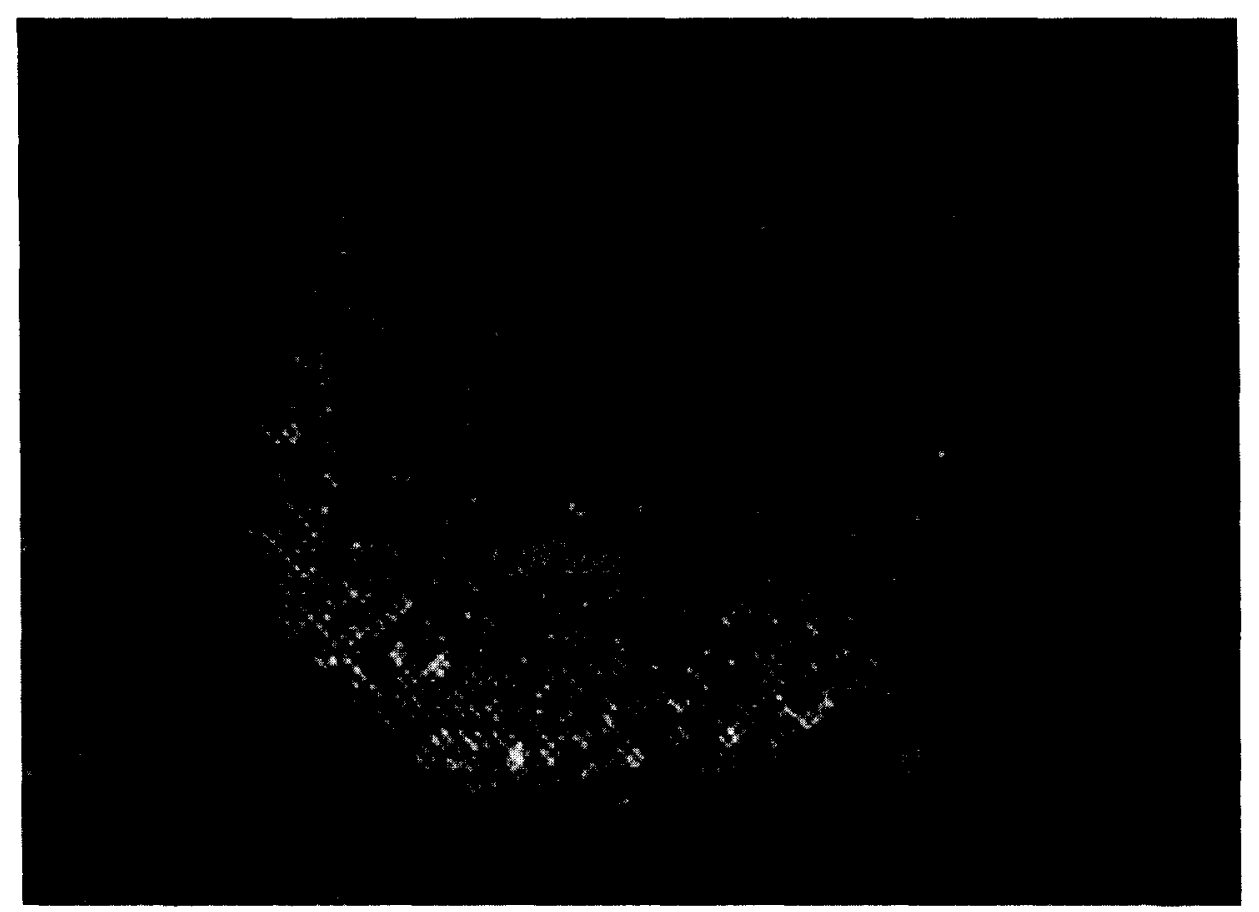

FIGURE 1. High resolution electron microscope micrograph of an $\mathrm{MgO}$ precipitate in a Cu matrix viewed along a [100] zone axis for both phases employing axial illumination; this image was recorded at a defocus value of 69.4 $\mathrm{nm}$ at an operating voltage of $300 \mathrm{kV}$. Atomic columns both in the $\mathrm{MgO}$ precipitate and the $\mathrm{Cu}$ matrix show the same crystallographic orientation -- cube-on-cube. This MgO precipitate has a diameter of $13 \mathrm{~nm}$.

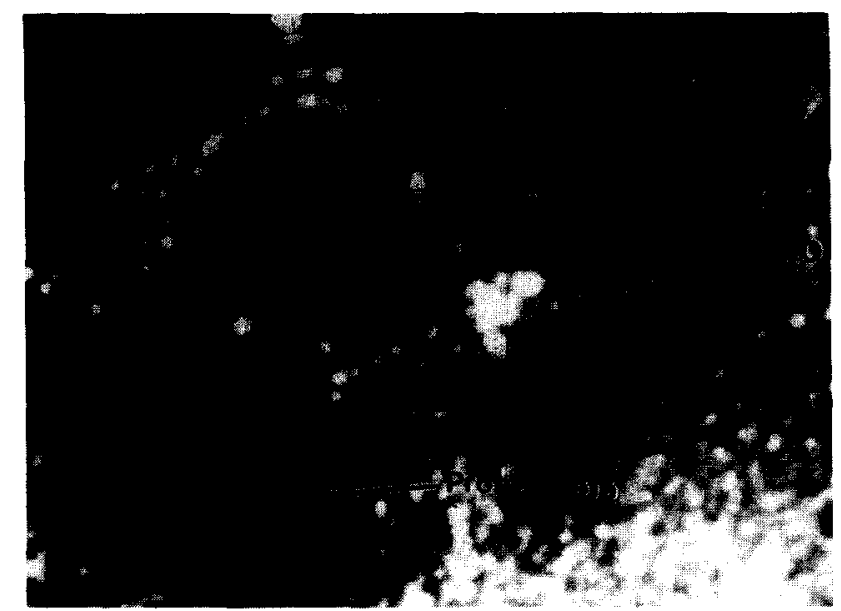

FIGURE 2: Field-ion microscope image of an $\mathrm{MgO}$ precipitate in a Cu matrix. The (111) plane of the $\mathrm{MgO}$ precipitate is parallel to the (111) plane of the $\mathrm{Cu}$ matrix. The diameter of the $\mathrm{MgO}$ precipitate is approximately 7.3 $\mathrm{nm}$. The neon imaging gas is at $8 \cdot 10^{-4} \mathrm{~Pa}$ gauge pressure and the temperature of the field ion microscope specimen is $40 \mathrm{~K}$. 


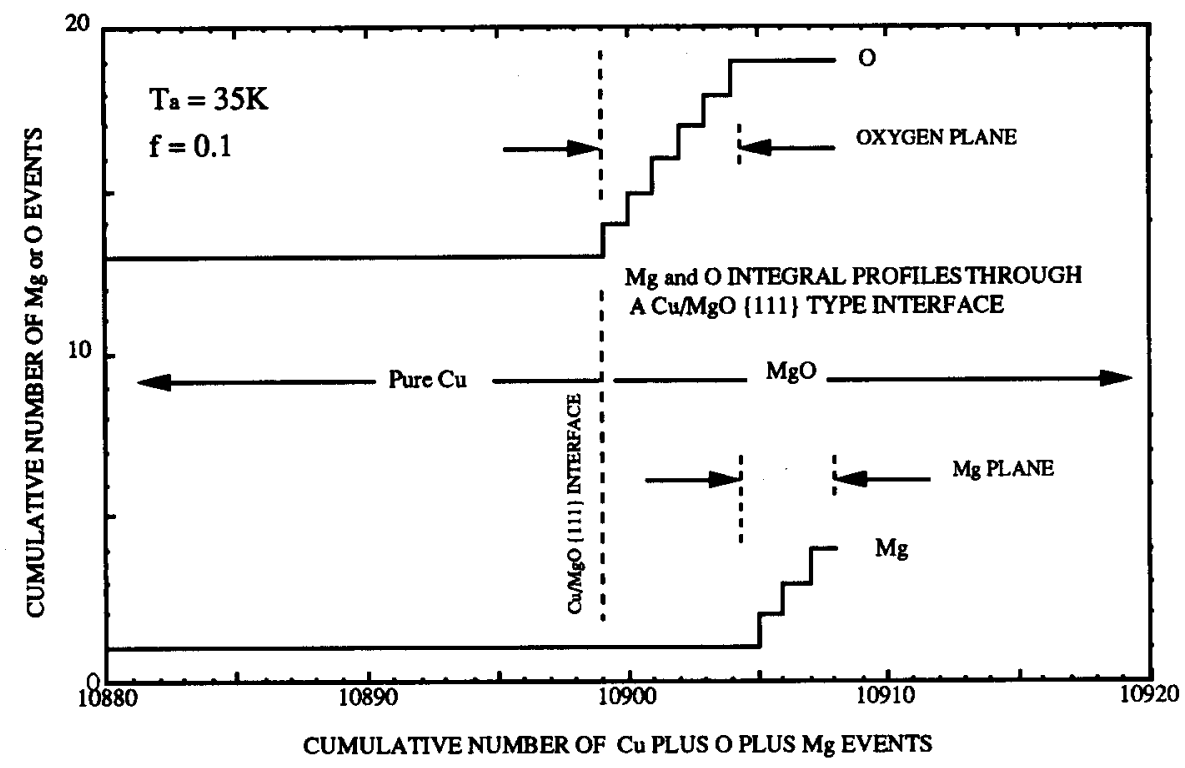

FIGURE 3: An integral profile across a $\mathrm{Cu} / \mathrm{MgO}$ (111) interface detected during a random area analysis; this profile was recorded at a specimen temperature of $35 \mathrm{~K}$, a pulse fraction of 0.1 , and a pulse frequency of $15 \mathrm{~Hz}$. The plot is the cumulative number of $\mathrm{Mg}$ or $\mathrm{O}$ ions detected versus the cumulative number of $\mathrm{Cu}$ plus $\mathrm{Mg}$ plus $\mathrm{O}$ ions detected. The $\mathrm{Cu}$ signal -- not exhibited -- disappears at the $\mathrm{Cu} / \mathrm{MgO}$ (111) interface and then the signal is 100 at. \% O until the first (222) plane has been completely removed by the field evaporation process, and then the next (222) plane is 100 at. \% Mg. This result indicates directly that the sequence of planes across this (111) heterophase interface is CulOIMg... . The depth resolution for this chemical composition profile is $\left(\mathrm{d}_{222}\right)_{\mathrm{MgO}}=$ $a_{0} /(2 \sqrt{3})$, where $a_{0}$ is the lattice parameter of $M g O(0.420 \mathrm{~nm})$, and is equal to $0.121 \mathrm{~nm}$. The data displayed in this integral profile has not undergone any deconvolution process. Note that the number of oxygen events detected before the $\mathrm{Cu} / \mathrm{MgO}$ (111) interface is reached is 13 out of a total number of 10,899 events ( $\mathrm{Cu}$ plus $\mathrm{Mg}$ plus $\mathrm{O}$ ); and the number of $\mathrm{Mg}$ events detected before this same interface is reached is 1 out of a total of 10,899 events ( $\mathrm{Cu}$ plus $\mathrm{Mg}$ plus $\mathrm{O}$ ); thus, the respective concentrations of oxygen and magnesium in the Cu matrix are $\approx 10^{-3}$ at. fr oxygen and $\approx 9 \cdot 10^{-5}$ at. fr. magnesium. 